\title{
Effect of the entomopathogenic fungus, Beauveria bassiana, combined with diatomaceous earth on the red flour beetle, Tribolium castaneum (Herbst) (Tenebrionidae: Coleoptera)
}

\author{
Muhammad Rizwan ${ }^{1 *}$, Bilal Atta ${ }^{1}$, Misbah Rizwan², Arshed Makhdoom Sabir ${ }^{1}$, Zafar Ullah Shah ${ }^{1}$ and \\ Mubashar Hussain ${ }^{3}$
}

\begin{abstract}
An assay was designed to evaluate the efficacy of each entomopathogenic fungus, Beauveria bassiana, and diatomaceous (DE) and their combinations at concentrations of $1 \times 10^{6}$ and $1 \times 10^{8}$ conidia kg $^{-1}$ of wheat and 200 and $400 \mathrm{ppm}$, respectively, on the red flour beetle, Tribolium castaneum (Herbst) (Tenebrionidae: Coleoptera), infesting wheat. Percent mortality of $T$. castaneum was recorded after 7, 14, and 21 days. Percent mycosis on dead cadavers was assessed after 21 days. Alive adults were removed from plastic jars after 21 days and kept for the next 60 days to assess the progeny production. The results indicated that the highest concentrations of B. bassiana and $D E$ in their combinations were more effective for the virulence and progeny suppression of $T$. castaneum. Maximum

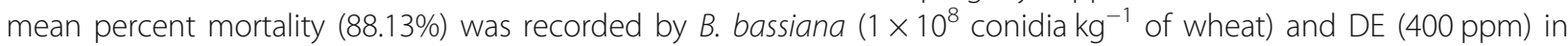
their combination after a 21-day exposure interval, while a minimum percent mean mortality (10.00\%) was recorded by B. bassiana $\left(1 \times 10^{6}\right.$ conidia $\mathrm{kg}^{-1}$ of wheat) alone. The maximum percent mycosis $(78.89 \%)$ on dead cadavers was recorded at a low concentration rate $\left(1 \times 10^{6}\right.$ conidia/ $\left./ \mathrm{kg}\right)$ of $B$. bassiana. Mean progeny adult emergence was the highest (62.67 adults) at the low concentration of B. bassiana alone. Present studies showed that $B$. bassiana and DE are more effective in combination against $T$. castaneum on wheat as both substances are advantageous.
\end{abstract}

Keywords: Beauveria bassiana, Diatomaceous earth, Tribolium castaneum, Wheat grains, Virulence, Progeny

\section{Background}

The red flour beetle, Tribolium castaneum (Herbst) (Tenebrionidae: Coleoptera), is among the most destructive insect pests of stored products all around the world (Mahroof and Hagstrum 2012). Both larvae and adults cause damage to the grains. Studies showed that insects cause about $5-10 \%$ of world's grain production losses. These losses extend to $50 \%$ in sultry countries where heat and moisture run high during summer season (Ahmad and Ahmad 2002).

\footnotetext{
* Correspondence: muhammad.rizwan@aari.punjab.gov.pk

${ }^{1}$ Rice Research Institute, Kala Shah Kaku, Punjab, Pakistan

Full list of author information is available at the end of the article
}

The insecticides are a common and effective tool acting as grain protectants against stored products' insect pests in Pakistan and worldwide. However, with the presence of insecticide resistance in insects, increasing demands for residue-free food products and environmentally safe practice, attempts have been made to find non-toxic and environmentally safe alternative protectants.

The possible use of entomopathogenic fungi (EPF), as a non-chemical alternative to traditional chemical products for cereal grains, has acknowledged increased attention during the recent years (Moore et al. 2000 and Lord 2001). EPF have a reuse capacity as they persist on the product and could recycle in the cadavers under certain environmental conditions, reestablishing further inoculum 
in the grains. Hence, while persistence is considered as a disadvantage in the case of customary grain protectants, it is an advantageous property in the case of fungi (Stathers 2002).

Diatomaceous earth (DE) is one of the known non-chemical substances and the most promising alternative to systematic use of insecticides (Vayias and Stephou 2009). DE is a naturally occurring non-toxic, non-chemical, and safe substance for controlling the stored grain insect pests with a unique mode of action for bruising and desiccation (Subramanyam and Roesli 2000). There are commercially available formulations of $D E$ that have been proved effective for a number of insect species with different concentrations on various stored grains. However, the efficacy of DE often varies with the formulations, treatment methodology, treated commodity, and other factors (Athanassiou et al. 2007 and 2008).

Both DE and EPF as grain protectants have different mechanisms of action and affect the insect cuticle, so their use in combination has been proposed by scientists as means of minimizing the applied doses (Akbar et al. 2004). Akbar et al. (2004) testified that the blend of Beauveria bassiana with the diatomaceous earth had a synergistic effect and better results against the larvae of T. castaneum. Furthermore, since both substances EPF and DE persist on the grains, it appears that such a mixture may have a certain gain as a durable and long-term protectant. Recent studies indicated that Sitophilus oryzae (L.), T. castaneum, and Rhyzopertha dominica (Fab.) are susceptible to Metarhizium anisopliae (Metsch.) Sorokin, B. bassiana, and DE (Michalaki et al. 2006).

In the present study, the possibility of a long-term safety of wheat grains against $T$. castaneum, through the collective use of $B$. bassiana and DE, was assessed. In addition to parental adult mortality, the rate of mycosis and progeny production of $T$. castaneum on the treated kernels was evaluated.

\section{Materials and methods Insect culture}

Adults of T. castaneum were obtained from the culture that reared in the laboratory on wheat flour at $28 \pm 2{ }^{\circ} \mathrm{C}$ and $65-75 \%$ R.H. The cultures were kept at the stored grain management cell, Department of Entomology, University of Agriculture, Faisalabad, Pakistan. All adult insects used in these tests were 67 days old.

\section{Grains}

Untreated, uncontaminated, and infestation-free grains of wheat (var. Galaxy) were used in the tests. Wheat grains were obtained from the 2017 harvest. The grain moisture content, as determined by the Grain Moisture
Tester RICETER f505 (Kett Electrical Laboratory, Tokyo, Japan), was $11.7 \%$. The grains were held at an ambient condition for 7 days to equilibrate to the desired $\mathrm{RH}$ before use in the experiments.

\section{Fungal formulations}

The strain of B. bassiana isolate used in this study was obtained from dead cadavers of rice leaf folder, Cnaphalocrocis medinalis (Guenée) (Rizwan et al. 2019). The fungus was then sub-cultured on Potato Dextrose Agar (PDA) plates for bulk generation of the fungal conidia. For bulk conidial production, plates were incubated for 14 days at $20 \pm 1{ }^{\circ} \mathrm{C}$ and $16 \mathrm{~h}$ light per day. Then, the conidia were collected by scraping the conidial layers developed on the plate surface by a sterilized scalpel. The collected conidia were mixed into $100 \mathrm{ml}$ sterile distilled water and filtered through muslin cloth. The fungal conidia and dust carrier were mixed at 1:4 ratio for formulation preparation (Kavallieratos et al. 2006). The conidia collected from strain were comprehensively mixed with the inert carrier ash in screw-capped bottles. Fungal conidia concentration was determined in the conidial suspension, using a hemocytometer. Two concentrations of B. bassiana were prepared, containing $1 \times 10^{6}$ and $1 \times$

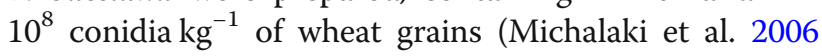
and Kavallieratos et al. 2006).

\section{DE formulation}

The DE formulation Diafil 610, used in this study, was manufactured by Celite Corporation (Lompoc, CA, USA). It contains $89 \%$ amorphous $\mathrm{SiO}_{2}, 4.0 \%$ aluminum oxide $\left(\mathrm{Al}_{2} \mathrm{O}_{3}\right), 1.7 \%$ iron oxide $\left(\mathrm{Fe}_{2} \mathrm{O}_{3}\right), 1.4 \% \mathrm{CaO},<1 \%$ $\mathrm{MgO}$ and $\mathrm{K}_{2} \mathrm{O}$, and $3 \%$ moisture. This DE was used at concentrations of 200 and $400 \mathrm{ppm}$ (equivalent to 0.20 and $0.40 \mathrm{~g} / \mathrm{kg}$ of wheat grains, respectively).

\section{Grain treatment}

Eight concentrations of EPF, DE, and their combinations were tested, i.e., the lowest concentration $\left(1 \times 10^{6} \mathrm{co}\right.$ nidia $\mathrm{kg}^{-1}$ of wheat) of the fungus alone, the highest concentration $\left(1 \times 10^{8}\right.$ conidia $\mathrm{kg}^{-1}$ of wheat $)$ of the fungus alone, the lowest concentration $(200 \mathrm{ppm})$ of $\mathrm{DE}$, the highest concentration $(400 \mathrm{ppm})$ of $\mathrm{DE}$ alone, and the combinations of low fungal concentration $\left(1 \times 10^{6} \mathrm{co}-\right.$ nidia $\mathrm{kg}^{-1}$ of wheat) + low DE concentration (200 ppm),

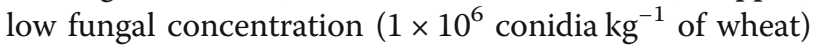
+ high DE concentration (400 ppm), high fungal concentration $\left(1 \times 10^{8}\right.$ conidia $\mathrm{kg}^{-1}$ of wheat $)+$ low DE concentration $(200 \mathrm{ppm})$, and high fungal concentration $(1 \times$ $10^{8}$ conidia $\mathrm{kg}^{-1}$ of wheat) + highest DE concentration $(400 \mathrm{ppm})$. For each grain treatment replication, lots of $1000 \mathrm{~g}$ wheat grains were organized and the particular quantity of fungus ( $1 \mathrm{~g}$ for each concentration corresponding to $1 \times 10^{6}$ and $1 \times 10^{8}$ conidia $\mathrm{kg}^{-1}$ of wheat) 
and DE $(0.20$ and $0.40 \mathrm{~g})$ were added. These lots were introduced in plastic jars $(24 \times 14 \times 14 \mathrm{~cm})$, and the jars were shaken manually for approximately $5 \mathrm{~min}$ to attain an equal dispersal of the dust on the whole grain mass. There was an additional untreated lot which served as control. All jars were kept in a laboratory at $28 \pm 2{ }^{\circ} \mathrm{C}$ and $65 \pm 5 \% \mathrm{RH}$ during the whole experimental period.

\section{Bioassays}

The post treatment efficacy for $F_{1}$ was observed for the time period of 2 months. Wheat batches of $1 \mathrm{~kg}$ were used to apply different treatments, viz., B. bassiana alone, DE alone, and their combinations. Nine samples (eight treatments and one control), each of $50 \mathrm{~g}$, of wheat were used in this experiment. Each sample was placed in a cylindrical plastic jar $(24 \times 14 \times 14 \mathrm{~cm})$ with a top covered with muslin cloth for aeration, and 40 adults of $T$. castaneum were introduced into each jar. These jars were placed in a laboratory at room temperature and $65 \pm 5 \% \mathrm{RH}$ (Kavallieratos et al. 2006). The desired $\mathrm{RH}$ in the laboratory was maintained by using a humidifier. The number of dead adults was counted after (7, 14 , and 21 days) in treated and untreated jars. The adults were classified as dead (unable to move even with stimulus) and alive (moving/or showing signs of activity). Thus, the data for mortality was recorded. The adults were removed from the jars after final observation. The mycosis data were recorded from the dead cadavers of $T$. castaneum that were collected from each treatment upon mortality assay termination. These cadavers were washed (two to three times) by $0.05 \%$ sodium hypochlorite solution, followed by three to four washings in distilled water, and then placed on PDA plates. These were incubated at $25 \pm 2{ }^{\circ} \mathrm{C}$ and $75 \pm 5 \% \mathrm{RH}$ for 1 week and then observed under a microscope for white fungal growth.

\section{Progeny production counts}

The dead and alive adults were removed from the jars, and these jars were placed undisturbed for another 60 days to ascertain the progeny emergence. After the completion of 60 days, the emerged adults were counted in each jar.

\section{Data analysis}

The counts for mortality rates were converted into percent and then analyzed using Statistix 8.1 software; however, the control mortality was very low and was not included in the analysis. Data were analyzed in three factorial CRD design, and the means were separated using the Bonferroni test at $P=0.05$.

\section{Results and discussion \\ Mortality of $T$. castaneum}

Main effects of different EPF and DE (alone and in combination), exposure intervals, and concentrations on percent mortality of $T$. castaneum were highly significant $(P$ $<0.05$ ) (Treatments: $F_{3,71}=602.71$, Exposure intervals: $F_{2}$, $71=551.46$, Concentrations: $F_{1}, 7_{1}=178.32$ ). Moreover, highly significant effects of interactions among Treatment $\times$ Exposure intervals, Treatment $\times$ Concentrations, and Exposure intervals $\times$ Concentrations were also observed for percent mortality $(P<0.05)$ (Treatment $\times$ Exposure intervals: $F_{6,71}=18.73$, Treatment $\times$ Concentrations: $F_{3,71}$ $=4.90$, Exposure intervals $\times$ Concentrations: $F_{2,71}=6.29$ ). Non-significant effects of interaction among Treatment $x$ Exposure intervals $\times$ Concentrations were recorded for percent mortality $(P>0.05)\left(F_{6,71}=1.43\right)$.

Main effects of different concentrations of EPF alone and mixed with DE on percent mycosis recovered from dead cadavers of $T$. castaneum were highly significant $(P<0.05)$ (Treatments: $F_{2}, 71=106.19$, Concentrations: $\left.F_{1,17}=15.69\right)$. Moreover, non-significant effects of interaction among Treatment $\times$ Concentrations were recorded for percent mycosis $(P>0.05)\left(F_{2,17}=1.43\right)$.

Main effects of different EPF and DE (alone and in combination) and concentrations on progeny production of $T$. castaneum were highly significant $(P<0.05)$ (Treatments: $F_{3,35}=30.03$, Concentrations: $\left.F_{2}, 35=1353.83\right)$. Moreover, highly significant effects of interaction among Treatment $\times$ Concentrations were recoded for progeny production $(P<0.05)\left(F_{6,35}=7.63\right)$.

Mortality of $T$. castaneum in all treatments was significantly different from each other. Long exposure interval and the highest concentration had a positive effect on the mortality rate of $T$. castaneum. The combinations gave better results than single concentrations of EPF and DE. EPF-treated wheat alone gave a maximum mortality rate $(31.67 \%)$ at the highest concentration $\left(1 \times 10^{8}\right.$ conidia $\mathrm{kg}^{-1}$ of wheat) as compared to $24.17 \%$ at the lowest concentration $\left(1 \times 10^{6}\right.$ conidia kg-1 of wheat). In the same way, the highest concentration of DE (400 ppm) alone gave more mortality $(49.17 \%)$ than the lowest concentration $(200 \mathrm{ppm})$ after a 21-day exposure interval. Similarly, combinations of EPF and DE gave maximum mortality percent $(88.33 \%)$ at maximum concentration $\left(1 \times 10^{8}\right.$ conidia $\mathrm{kg}^{-1}$ of wheat $\left.+400 \mathrm{ppm} \mathrm{DE}\right)$ after 21-day exposure time. The combinations of the lowest concentrations of EPF and DE gave less percent mortality as compared to higher concentration at combinations, but the level of $T$. castaneum mortality was high as compared to DE and the EPF alone (Fig. 1).

\section{Mycosis and progeny production}

The maximum percent mycosis $(78.89 \%)$ was recorded in the treatment of low concentration of fungal pathogen 


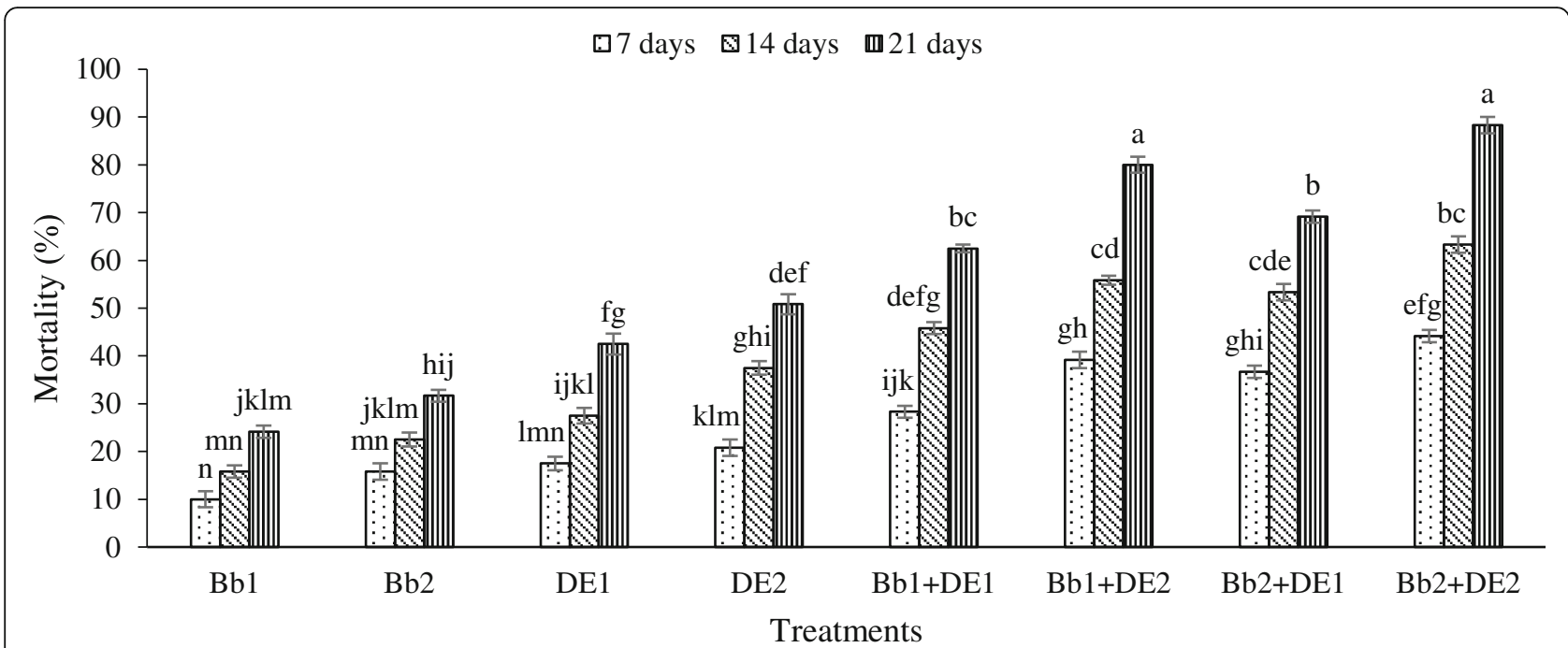

Fig. 1 Percent mortality (mean $\pm S E, n=3)$ of Tribolium castaneum in treated wheat with two concentrations of Beauveria bassiana $\left(1 \times 10^{6}\right.$ and $1 \times 10^{8}$ conidia kg $^{-1}$ of wheat) and DE (200 and $400 \mathrm{ppm}$ ) (alone and in combination) at weekly intervals

$\left(1 \times 10^{6}\right.$ conidia $\left./ \mathrm{kg}\right)$ and $\mathrm{DE}(200 \mathrm{ppm})$, while the minimum percent mycosis $(31.21 \%)$ was recorded in the treatment of higher dose combination of EPF $\left(1 \times 10^{8}\right.$ conidia/kg) with DE (400 ppm) (Fig. 2).

Maximum progeny production of T. castaneum (62.67 adults) in wheat grains treated with EPF and DE (alone and in combination) was recorded due to low concentration of EPF $\left(1 \times 10^{6}\right.$ conidia $\left./ \mathrm{kg}\right)$ alone, while minimum progeny production (2.67 adults) was recorded at high concentration of EPF $\left(1 \times 10^{8}\right.$ conidia $\left./ \mathrm{kg}\right)$ and DE $(400$ ppm), used in combination (Fig. 3).

EPF had been used previously for stored grain pest management with different concentrations at different time intervals. Dry conidial concentrations had different virulence against insect pests of stored grains (Kavallieratos et al. 2006). Based on the present studies, B. bassiana proved effectiveness against $T$. castaneum, but efficacy depended upon dose rate and exposure interval. Moreover, the addition of desiccant dust notably increased the effectiveness of EPF, when used in combination. Akbar et al. (2004) reported that the use of diatomaceous earth increased the mortality of $T$. castaneum larvae. Vassilakos et al. (2006) also reported an additive effect of $B$. bassiana, when used with DE against adults of $R$. dominica and $S$. oryzae. Athanassiou et al. (2006) stated that an addictive effect was not dependent

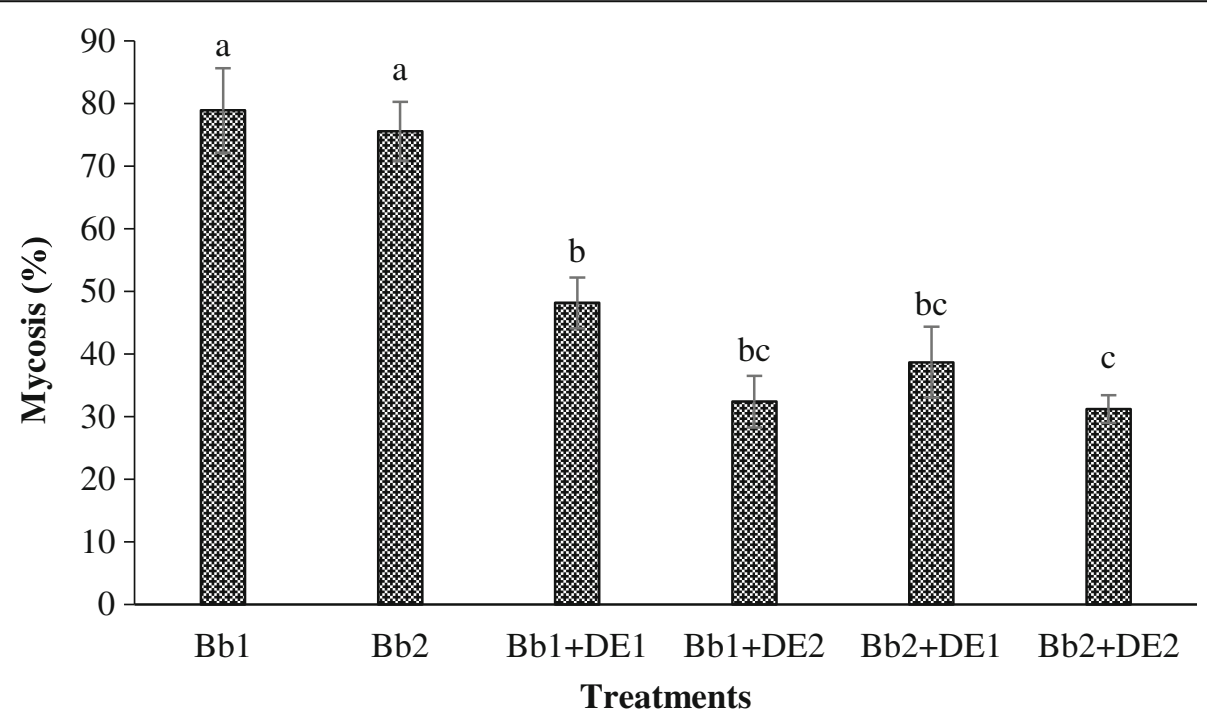

Fig. 2 Percent mycosis (mean $\pm \mathrm{SE}, n=3)$ in cadavers of Tribolium castaneum treated with two concentrations of Beauveria bassiana $\left(1 \times 10^{6}\right.$ and

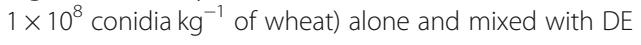




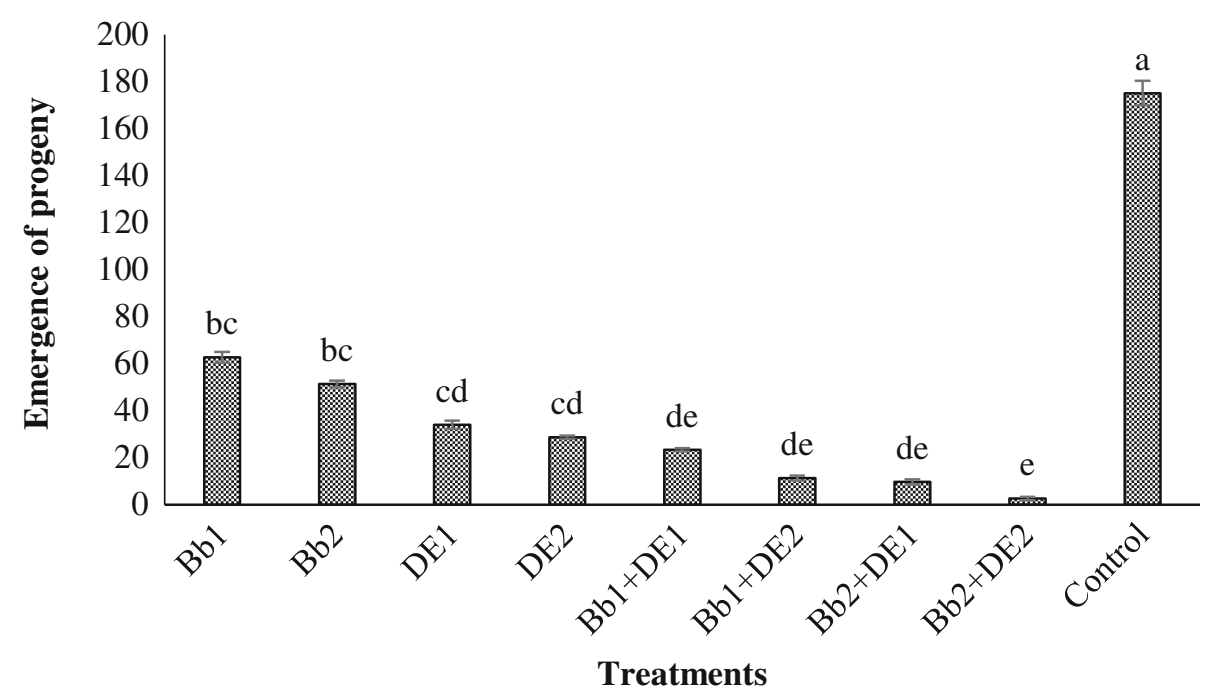

Fig. 3 Progeny production (mean $\pm \mathrm{SE}, n=3)$ of Tribolium castaneum treated with two concentrations of Beauveria bassiana $\left(1 \times 10^{6}\right.$ and $1 \times 10^{8}$ conidia $\mathrm{kg}^{-1}$ of wheat) and DE (200 and $400 \mathrm{ppm}$ ) (alone and in combination)

on the type and formulation of desiccant dust, which means all types of DEs can successfully be used for this purpose. Similarly, virulence of fungal strains differed remarkably against stored grain insect pests (Moore et al. 2000 and Stathers 2002), and addition of synergistic inert material was preferable than mass production of fungal strain. DE formulations produced much better results, and DEs could efficiently be least affected by the environment, which could retain their effectiveness for 8-9 months, when applied on wheat grains (Athanassiou et al. 2005), to 20 months, when applied to maize grains (Stathers et al. 2008). Vayias et al. (2006) also reported similar results for DEs on maize and wheat against Tribolium confusum. DEs slowly absorb moisture from the air, which reduce their efficacy (Subramanyam and Roesli 2000), while in case of fungi, spore persistence is an important distinctive characteristic (Thomas et al. 1997 and Stathers 2002). However, conidial activity declined with time (Moore et al. 2000). Batta (2004) found that the conidial viability of fungus decreased with time, but its insecticidal efficacy was not badly affected. This trend has also been reported in case of some greenhouse and field trials and pests such as the rice leaf roller, $C$. medinalis (Rizwan et al. 2019), and the whitefly Bemisia tabaci (Gennadius) (Batta 2003), respectively. Fungal pathogens are more advantageous in bio-control cases as these could recycle in cadavers producing conidiospores that are reintroduced into the eco-system (Thomas et al. 1997 and Stathers 2002). A high mortality rate was obtained in wheat in the case of combined use of EPF and DE against $T$. castaneum because it is a mobile pest, hence more chances of abrasion with DEs and picking fungal pathogen. Second, it might be that the use of wheat grains in this study as previous studies reported more efficacy of fungal pathogen and DEs against stored grain insect pest in case of wheat grains (Subramanyam and Roesli 2000; Athanassiou and Kavallieratos 2005 and Kavallieratos et al. 2005). DE efficacy is greatly attributed to the type of grains/cereals used for bioassay studies as wheat grains retain DE particles considerably as compared to maize (Athanassiou and Kavallieratos 2005), while Michalaki et al. (2006) reported a higher survival rate of $T$. confusum Jacquelin du Val larvae on flour rather than treated wheat with $M$. anisopliae and DE. The dead cadavers become the source of secondary infection and increase the efficacy of EPF (Thomas et al. 1997). High percent mycosis at a low dose had been recorded earlier by Tefera and Pringle (2003). This suggests that insects may resort to a less-treated stratum of grains, may oviposit and produce generations, or may have the ability to recover and continue to cause damage. Hence, the destruction of progeny is an equal important task with parental mortality.

\section{Conclusion}

This study suggested that a combination of EPF and DE provided a better long-term management of $T$. castaneum. Both substances had a lethal as well as a suppressive effect against progeny $\left(\mathrm{F}_{1}\right)$ production of the pest.

\section{Acknowledgements}

Not applicable

\section{Funding}

Not applicable 


\section{Availability of data and materials}

The datasets used and/or analyzed during the current study are available from the corresponding author on reasonable request.

\section{Authors' contributions}

Muhammad R, BA, and AMS planned the research and designed the methodology. Muhammad R and BA conducted the experiments. ZUS helped in the data analysis. Misbah $\mathrm{R}$ and $\mathrm{MH}$ drafted the manuscript. All the authors have read and approved the final manuscript.

\section{Ethics approval and consent to participate}

Not applicable

\section{Consent for publication}

Not applicable

\section{Competing interests}

The authors declare that they have no competing interests.

\section{Publisher's Note}

Springer Nature remains neutral with regard to jurisdictional claims in published maps and institutional affiliations.

\section{Author details}

${ }^{1}$ Rice Research Institute, Kala Shah Kaku, Punjab, Pakistan. ${ }^{2}$ Department of Biology, Government College for Women, Emanabad, Gujranwala, Pakistan. ${ }^{3}$ Department of Plant Breeding and Genetics, University of Agriculture, Faisalabad, Pakistan.

Received: 5 February 2019 Accepted: 12 April 2019

Published online: 07 May 2019

\section{References}

Ahmad M, Ahmad A (2002) Storage of food grains. Farm Outl 1:16-20.

Akbar W, Lord JC, Nechols JR, Howard RW (2004) Diatomaceous earth increases the efficacy of Beauveria bassiana against Tribolium castaneum larvae and increases conidia attachment. J Econ Entomol 97:273-280.

Athanassiou CG, Kavallieratos NG (2005) Insecticidal effect and adherence of PyriSecs in different grain commodities. Crop Prot 27:703-710.

Athanassiou CG, Kavallieratos NG, Economou LP, Dimizas CB, Vayias BJ, Tomanovic S, Milutinovic M (2005) Persistence and efficacy of three diatomaceous earth formulations against Sitophilus oryzae (Coleoptera: Curculionidae) on wheat and barley. J Econ Entomol 98:1404-1412.

Athanassiou CG, Kavallieratos NG, Meletsis CM (2007) Insecticidal effect of three diatomaceous earth formulations, applied alone or in combination, against three stored-product beetle species on wheat and maize. J Stored Prod Res 43:303-334.

Athanassiou CG, Kavallieratos NG, Vayias BJ, Panoussakis EC (2008) Influence of grain type on the susceptibility of different Sitophilus oryzae (L.) populations, obtained from different rearing media, to three diatomaceous earth formulations. J Stored Prod Res 44:279-284.

Athanassiou CG, Korunic Z, Kavallieratos NG, Peteinatos GG, Boukouvala MC, Mikeli NH (2006). New trends in the use of diatomaceous earth against stored-grain insects. In Proc 9 International Working Conf Stored Prod Prot, Sao Paulo. Brazil, pp 15-18.

Batta YA (2003) Production and testing of novel formulations of the entomopathogenic fungus Metarhizium anisopliae (Metsch.) Sorokin (Deuteromycotina: Hyphomycetes). Crop Prot 22:415-422.

Batta YA (2004) Control of the rice weevil (Sitophilus oryzae L., Coleoptera: Curculionidae) with various formulations of Metarhizium anisopliae. Crop Prot 23:103-108.

Kavallieratos NG, Athanassiou CG, Michalaki MP, Batta YA, Rigatos HA, Pashalidou FG, Balotis GN, Tomanovic Z, Vayias BJ (2006) Effect of the combined use of Metarhizium anisopliae (Metschinkoff) Sorokin (Deuteromycotina: Hyphomycetes) and diatomaceous earth for the control of three stored product beetle species. Crop Prot 25:1087-1094.

Kavallieratos NG, Athanassiou CG, Pashalidou FG, Andris NS, Tomanovic Z (2005) Influence of grain type on the insecticidal efficacy of two diatomaceous earth formulations against Rhyzopertha dominica (F) (Coleoptera: Bostrychidae). Pest Manag Sci 61:660-666.
Lord JC (2001) Desiccant dusts synergize the effect of Beauveria bassiana (Hyphomycetes: Moniliales) on stored-grain beetles. J Econ Entomol 94: 367-372.

Mahroof RM, Hagstrum DW (2012) Biology, behavior, and ecology of pests in processed commodities. In: Hagstrum DW, Philips TW, Cuperus G (eds) Stored product protection. Kansas State University, Manhattan, pp 33-44.

Michalaki M, Athanassiou CG, Kavallieratos NG, Batta YA, Balotis JN (2006) Effectiveness of Metarhizium anisopliae (Metschinkoff) Sorokin applied alone or in combination with diatomaceous earth against Tribolium confusum Jacquelin du Val: influence of temperature relative humidity and type of commodity. Crop Prot 25:418-425.

Moore D, Lord JC, Smith SM (2000) Pathogens. In: Subramanyam B, Hagstrum DW (eds) Alternatives to pesticides in stored-product IPM. Kluwer Academic Publishers, Dordreecht, pp 193-227.

Rizwan M, Atta B, Sabir AM, Yaqub M, Qadir A (2019) Evaluation of the entomopathogenic fungi as a non-traditional control of the Rice leaf roller, Cnaphalocrocis medinalis (Guenee) (Lepidoptera: Pyralidae) under controlled conditions. Egyp J Biol Pest Con 29:10.

Stathers T (2002) Entomopathogenic fungi in grain storage_-any lessons for Europe from elsewhere? In: Zdarkova E, Lukas J, Hubert J (eds) Proceedings of the Second Meeting of WG 4 of COST Action 842, Prague, pp 100-109.

Stathers TE, Riwa W, Mvumi BM, Mosha R, Kitandu L, Mngara K, Kaoneka B, Morris M (2008) Do diatomaceous earths have potential as grain protectants for small-holder farmers in sub-Saharan Africa? The case of Tanzania. Crop Prot 27:44-70.

Subramanyam B, Roesli R (2000) Inert dusts. In: Subramanyam B, Hagstrum DW (eds) Alternatives to pesticides in stored-product IPM. Kluwer Academic Publishers, Dordrecht, pp 321-380.

Tefera T, Pringle KL (2003) Effect of exposure method to Beauveria bassiana and conidia concentration on mortality, mycosis and sporulation in cadavers of Chilo partellus (Lepidoptera: Pyralidae). J Invertebr Pathol 84:90-95.

Thomas MB, Wood SN, Langewald J, Lomer CJ (1997) Persistence of Metarhizium flavoviridae and consequences for biological control of grasshoppers and locusts. Pestic Sci 49:47-55.

Vassilakos TN, Athanassiou CG, Kavallieratos NG, Vayias BJ (2006) Influence of temperature on the insecticidal effect of Beauveria bassiana in combination with diatomaceous earth against Rhyzopertha dominica and Sitophilus oryzae on stored wheat. Biol Control 38:270-281.

Vayias BJ, Athanassiou CG, Kavallieratos NG, Tsesmeli CD, Buchelos CT (2006) Persistence and efficacy of two diatomaceous earth formulations and a mixture of diatomaceous earth with natural pyrethrum against Tribolium confusum Jacquelin du Val (Coleoptera: Tenebrionidae) on wheat and maize. Pest Manag Sci 62:456-464.

Vayias BJ, Stephou VK (2009) Factors affecting the insecticidal efficacy of an enhanced diatomaceous earth formulation against three stored-product insect species. J Stored Prod Res 45:226-231.

\section{Submit your manuscript to a SpringerOpen ${ }^{\circ}$ journal and benefit from:}

- Convenient online submission

- Rigorous peer review

- Open access: articles freely available online

- High visibility within the field

- Retaining the copyright to your article

Submit your next manuscript at $\boldsymbol{\nabla}$ springeropen.com 